\title{
DIÁLOGOS POSSÍVEIS ATRAVÉS DO PROJOVEM
}

http://dx.doi.org/10.5902/217621711481

\author{
Maria da Luz Cavasotto Botao
}

Rede Municipal de Canoas, Brasil.

\begin{abstract}
Resumo
Pesquisou-se o Projovem, uma política de formação e inclusão para os jovens. Pla observação, análise qualitativa e pesquisa participante foi-se construindo textos que abordam os diversos discursos utilizados por este programa: que tipos de discursos se encontram entranhados desde a sua elaboração, passando por professores e alunos, de modo que, em tese, reafirmam o lugar de exclusão que os jovens ocupam na sociedade? Argumenta-se que devido à forma como está articulado o currículo, o modo de funcionamento e organização deste programa colabora para um alfabetismo funcional. As memórias escolares das séries iniciais, assim como as condições de vida dos alunos impregnam relatos colhidos nesta pesquisa. As trajetórias de repetências contínuas desses jovens nos fizeram indagar a construção do fracasso escolar. Os dados foram coletados por entrevistas, observações na escola onde ocorreu o Projovem na cidade de Canoas. Palavras-chave: Projovem, exclusão, inclusão, alfabetismo funcional, fracasso escolar.
\end{abstract}

\section{DIALOGUES POSSIBLE THROUGH OF PROJOVEM}

\begin{abstract}
It was researched Projovem, a formation and inclusion policy for the youth, through observation, qualitative analysis and participatory research, from which it is constructing texts that discuss the different discourses used by the program / context. What kinds of discourses are ingrained from its drafting, through passing teachers and students so that, theoretically, reaffirm the place of exclusion that young people already occupy in society. Due how the curriculum is articulated, the mode of operation and organization of this program, cooperate for a functional literacy. The initial series of school memories, as well as the living conditions of students, impregnate testimonies collected in this research. The trajectories of these young school failures continuous, in the initial series, made us investigate the construction of this failure at school. The data were collected through interviews, observations at the school where Projovem is held, in the city of Canoas.

Key-words: Projovem, exclusion, inclusion, functional illiteracy, school failure.
\end{abstract}




\section{Introdução}

partir de investigação para a conclusão do curso de Pedagogia da Ufrgs,
realizado sobre o programa Projovem, realizou-se observação, análise
qualitativa e pesquisa participante, a partir da qual foi-se construindo textos que abordam os diversos discursos utilizados no âmbito deste programa. Isso nos fez perceber um estranhamento quanto aos discursos relacionados com a concepção do programa, o que é feito por professores e alunos, de modo que, em tese, argumenta-se que o Projovem reafirma o lugar de exclusão que os jovens já ocupam na sociedade, bem como devido à forma como está articulado o currículo, o modo de funcionamento e organização deste programa, colabora para a manutenção do alfabetismo funcional.

O objetivo do programa é o retorno aos estudos da maior quantidade de jovens possível, limitando a quantidade mínima de alunos por sala de aula em 20 e no máximo 30 , sendo 5 turmas por núcleo. As memórias escolares das séries iniciais, assim como as condições de vida dos alunos, impregnam relatos colhidos nesta pesquisa. As trajetórias de repetências contínuas desses jovens, nas séries iniciais, nos fizeram indagar a construção deste fracasso escolar. Os dados foram coletados por pesquisa documental, entrevistas e observações na escola onde ocorreu o Projovem na cidade de Canoas.

\section{Medida provisória n. 238/2005}

O Projovem foi criado a partir de medida provisória n. 238/2005, como um programa nacional de inclusão de jovens: educação, qualificação e ação comunitária, apresentado pela Secretaria-Geral da Presidência da República, com condições de ser aprovado como programa experimental, nos termos do artigo 81 da LDB. A sua execução acontece em regime de colaboração com as secretarias municipais de educação, a quem cabe à certificação dos alunos.

\section{Problematização}

Uma medida provisória somente pode ser colocada em pauta numa situação de exceção e emergência. Qual seria a situação de exceção e de emergência neste caso? Será que o maior interesse do governo é promover a volta aos estudos? Que tipo de formação poderá ser obtida em tão pouco tempo - 18 meses? Ou será que o objetivo maior é apenas o controle social? Ou para justificar o emprego de verbas financiadas pelos órgãos multilaterais no que diz respeito à educação?

De acordo com Fonseca (2007, p. 2),

a perspectiva de reformar o capital através de ações pontuais, visando minimizar as desigualdades produzidas pelo capitalismo e, assim, melhorar as condições de vida do imenso contingente populacional que vive abaixo da linha da pobreza - portanto na miséria - através de políticas focais constitui uma efêmera possibilidade. Nessa situação, insere-se o Estado ampliado fortalecendo um sentido de alivio das demandas e, em contrapartida, enfraquecendo a organização e luta da parcela inserida nas políticas compensatórias.

\section{A quem se destina o Projovem}

Inicialmente o Projovem destinava-se a jovens com idade entre 18 e 24 anos, posteriormente esse idade ampliou-se para 15 a 29 anos, que tenham cursado, no 
mínimo, a 4aㅗ série do ensino fundamental, mas não tenham concluído a 8aㅗ série, e que não tenham vínculo empregatício formal. Aos alunos devidamente matriculados será concedido um auxílio financeiro mensal no valor de $R \$ 100,00$. A formação integral compreenderá atividades de formação escolar (800 horas), qualificação profissional (350 horas) e desenvolvimento de ação comunitária (50 horas), somando 1.200 horas presenciais.

\section{Princípios político-pedagogicos}

O Projovem tem como princípios político-pedagogicos:

a) integração entre educação fundamental, qualificação profissional e ação comunitária;

b) aliar teoria e prática articuladas à dimensão educativa do trabalho e à participação cidadã.

c) organização curricular inovadora e flexível, que busca romper com duas dicotomias: educação geral versus formação profissional e educação versus ação cidadã.

\section{Objetivos do Projovem}

a) Oportunizar a experimentação pelos jovens, em novas formas de interação;

b) apropriar-se de novos conhecimentos;

c) re-elaborem suas próprias experiências e sua visão de mundo;

d) re-posicionem quanto à sua inserção social e profissional;

e) o projovem é concebido como instrumento de inclusão social em sentido pleno.

Ainda conforme a legislação, o Projovem deve contribuir para a reinserção do jovem na escola; a identificação de oportunidades de trabalho e capacitação dos jovens para o mundo do trabalho; a identificação, elaboração de planos e desenvolvimento de ações comunitárias; a inclusão digital dos jovens, para que desfrutem desse instrumento de inserção produtiva e de comunicação (art. $3^{\circ}$ ).

\section{Problematização}

Um destaque que pode ser é o caso da medida provisória, quanto alguém pensou pelo aluno e no lugar do professor, resolvendo o problema das multirrepetências e exclusões do ensino formal criando um novo programa, na intenção de solucionar os problemas descritos. Professores e alunos devem se basear em um manual para aprender e ensinar. Será que é possível uma formação ou cidadania instituída por decreto?

Conforme Freire (1996, p. 56 ),

do ponto de vista democrático em que me situo, mas também do ponto de vista da radicalidade metafísica em que me coloco e de que decorre minha compreensão o homem e da mulher como seres históricos e inacabados e sobre o que se funda a minha inteligência do processo de conhecer, ensinar é algo mais que um verbo transitivo-relativo. Ensinar inexiste sem aprender e vice-versa. 
Além da enunciação dos objetivos acima, que ficam apenas na formalidade, as dificuldades encontradas pelos professores para produzirem os resultados anunciados também são grandes, já que sua formação não o permite. Devido ao tempo reduzido para que se efetive a aprendizagem de quatro séries em 18 meses, algo do conteúdo programático dessas séries será perdido.

Um exemplo foi o da informática, que em maio de 2007, quando iniciei a observação, eles ainda não tinham internet e nem aulas de informática, pois os professores não haviam sido preparados para trabalhar com o Linux.

\section{Questionário, repetências e a escola dos sonhos}

Transcrevo, literalmente, as palavras dos alunos do Projovem.

Quais eram as condições financeiras da sua família enquanto estava nas séries iniciais?

Nome: L. Sexo: F. Turma: 12 Idade: 25 anos.

"Não era muito boa e nem ruim, minha mãe trabalhava fora e nunca faltou nada pra mim".

Nome: D. Sexo: F. Turma: 12 Idade: 22 anos.

"Normal, somos pobres".

Nome: E. Sexo: F. Turma: 12 Idade: 23 anos.

"Muito critica".

Nome: F. Sexo: M. Turma: 13 Idade: 21 anos.

"Não muito boa se eu quizese alguma coisa tinha que lutar".

Nome: S. Sexo: F. Turma: 12 Idade: 22 anos.

1. Em que séries, e quantas vezes ocorreram repetências?

" $2^{\mathrm{a}}$ serie, $4^{\mathrm{a}}$ serie e $6^{\mathrm{a}}$ serie, repeti 5 vezes de ano".

2. Se pudesse retroceder no tempo você voltaria para a mesma turma e série em que parou? Justifique.

"Sim. Eu tentaria di novo, pois eu parei na $6^{\mathrm{a}}$ serie de estudar, e também por que faltou 2 pontos só $\mathrm{p} /$ mim passar de ano e a prof. não deu esses 2 pontinhos, isso desanimou e parei de estudar".

3. Quais eram as condições financeiras da sua família enquanto estava nas séries iniciais?

"Era mais ou menos, nem muito e nem pouco".

Nome: K. Sexo: F. Turma: 12 Idade: 21 anos.

1. Em que séries, e quantas vezes ocorreram repetências?

" $4^{\mathrm{a}}$ serie 1 vez $6^{\mathrm{a}}$ serie 2 vezes parei na $2^{\mathrm{a}}$ vez porque fiquei gravida" 
2. Se pudesse retroceder no tempo você voltaria para a mesma turma e série em que parou? Justifique.

"Não por que os professores eram muito estúpidos".

3. Como seria a escola dos teus sonhos?

"Gostaria que a escola tivesse professores percistentes, bem organizados e com muito paciência para explicar todas as matérias".

Nome: M. Sexo: M. Turma: PJ. 12 Idade: 18 anos.

1. Em que séries e quantas vezes repetiu $o$ ano?

" $3^{\mathrm{a}} 2 \mathrm{x} 5^{\mathrm{a}} 2 \mathrm{x}$ "

2. Se pudesse retroceder no tempo você voltaria para a mesma turma e série em que parou? Justifique.

"Não. Porque se não tivesse parado de estudar não estaria tendo essa maravilhosa chance que estou tendo em estar estudando e conseguindo meu diploma".

3. Quais eram as condições financeiras da sua família enquanto estava nas séries iniciais?

"Baixa renda".

4. Qual seria a escola dos seus sonhos?

"Não consigo imaginar escola melhor do que a que estou".

Nome: A. Sexo: F. Turma: 11 Idade: 21 anos.

1. Em que séries e quantas vezes repetiu o ano?

"Na $2^{\mathrm{a}}$ serie $2 \mathrm{x}$

$\mathrm{Na} 4^{\mathrm{a}}$ serie $1 \mathrm{x}$

2. Se pudesse retroceder no tempo você voltaria para a mesma turma e série em que parou? Justifique.

"Sim para mim poder aprender mais e força mais a cabeça"

Nome: F. Sexo: M. Turma: 13 Idade: 21 anos.

1. Em que séries e quantas vezes repetiu de ano?

"Rodei 3 vezes na quinta serie"

2. Se pudesse retroceder no tempo você voltaria para a mesma turma e série em que parou? Justifique.

"Sim mais agora iria ser diferente antes eu era muito jovem não queria nada com nada se eu tivesse a cabeça que eu tenho eu nunca teria rodado"

3. Qual seria a escola dos teus sonhos?

"Para mim não existe escola dos sonhos uma escola foi feita para estudarmos" 
Nome: F. Sexo: M. Turma: 14 Idade: 23 anos.

1. Em que séries e quantas vezes repetiu o ano?

" 2 vezes $2^{a}$ e $3^{a "}$

2. Se pudesse retroceder no tempo você voltaria para a mesma turma e série em que parou? Justifique.

"Não. Pois acho que seria muito ruim"

3. Qual seria a escola dos teus sonhos?

"Uma escola com bastante oportunidades de cursos para uma profiçao"

Nome: K. Sexo: F. Turma: 14 Idade: 18 anos.

1. Em que séries e quantas vezes repetiu o ano?

" 1 a repeti uma

6⿳亠丷厂 repeti uma

$7^{a}$ repeti três".

2. Se pudesse retroceder no tempo você voltaria para a mesma turma e série em que parou? Justifique.

"Sim, porque a bagunça era boa".

3. Qual seria a escola dos teus sonhos?

"A escola dos meus sonhos. $1^{\circ}$ tem que ser toda de rosa a decoração até as mesas.

$2^{\circ}$ tem que ter um shooping dentro da escola. $3^{\circ} \mathrm{E}$ tem que ser no centro onde tenha bastante movimento".

Problematização

Como se pode notar, a história de vida destes alunos transborda quanto ao relato sobre professores que, por uma razão ou outra, não se mostravam capazes ou mesmo capacitados para realizar uma mediação eficaz entre o conhecimento e os alunos. As suas repetências denotam que os próprios alunos também têm seus problemas. Dentre eles se incluem a baixa renda, gravidez precoce, trabalho precoce, reforçando em grande medida a tese de que ao invés de estarem estudando em idade própria, estariam ajudando em casa ou mesmo sendo aproveitados em trabalhos extra-domiciliares, como no caso dos rapazes, que são minoria no programa. São trabalhos invisíveis, como empregos informais.

\section{Conteúdo do guia de estudo - unidade I (p. 210-211)}

Seu pai ou sua mãe trabalharam ou trabalham com carteira assinada?

Viveram ou vivem de um negócio próprio?

Tópicos e textos:

3- Todos buscam um "bom emprego"

Ter um bom emprego, ontem ou hoje, significa trabalhar para uma empresa conhecida e bem organizada. Uma empresa desse tipo assina a carteira, concede 
benefícios, paga bem e oferece oportunidades de crescimento profissional aos seus funcionários. Ter um emprego assim contribui muito para organizar a vida do trabalhador e de sua família: comprar a prazo, adquirir uma casa com financiamento.

4- Muitos lutam para montar um negócio próprio

Montar um negócio também é uma forma de estabelecer-se na vida. [...] Um negócio que garanta uma renda mensal suficiente para manter a família, educar os filhos, também é uma forma de conquistar estabilidade na vida. [...]

Você já teve experiência de trabalho com carteira assinada?

Já tentou montar um negócio próprio?

O que prefere?

O que devemos esperar dessas duas opções hoje em dia?

5 - Mudanças no mundo do trabalho

Mas, infelizmente, o que se vê no país inteiro e mesmo no mundo todo é que, para quem vive do trabalho, esses dois caminhos estão cada vez mais difíceis. Os trabalhadores em geral e principalmente os jovens vivem um momento de muita insegurança, de muita incerteza.

Problematização

O que poderia provocar no jovem, ao ler os dizeres que estão acima, referentes à qualificação profissional? Estaria o manual induzindo as vidas destes jovens apenas para um tipo de concepção de vida, mais precisamente a neoliberal? Entretanto, nos diz Freire (1996), o educando sujeitado ao 'bancarismo' não está fadado a fenecer, mas por causa do processo mesmo de aprender, deve dar a volta por cima e superar o autoritarismo de tal erro epistemológico.

\section{Conteúdos do guia - qualificação para o trabalho (p. 210 e 211)}

As coisas estão mudando rapidamente no mundo do trabalho. Novas profissões estão surgindo. [...] Por outro lado, velhas profissões estão extintas ou em processo de extinção, como a de tipógrafo.

1. Pesquise sobre profissões extintas ou em extinção.

2. Você conhece caso de alguém que teve sua profissão extinta? Conte.

3. Pesquise sobre novos produtos que estão no nosso dia-a-dia. Reflita sobre a utilidade deles.

A verdade é que as empresas estão contratando menos. E os motivos são vários. $A$ tecnologia está substituindo o trabalho humano. Novas formas de organizar o trabalho exigem que 0 trabalhador assuma várias funções, assumindo o lugar de muitos. Nos últimos 20 anos a economia teve um crescimento pequeno, contribuindo pouco para criar novos empregos.

Problematização

O que esta lição não aponta é sobre as possibilidades de o programa também não propiciar o que divulga aos estudantes. A alfabetização funcional que continuam recebendo pelo programa não dá conta de que os alunos sejam capazes de produzirem uma crítica quanto ao seu conteúdo. O que essa lição não aborda é sobre a extinção do 
próprio trabalhador devido a existência dos sobrantes (Fonseca, 2007), do trabalho infanto-juvenil e também dos avanços tecnológicos.

É claro que não posso dizer que os problemas do desemprego não existem, por outro lado, a mídia divulga em tempo integral as dificuldades encontradas quanto ao aumento do desemprego no mundo inteiro. Dessa forma influencia e fixa na mente do povo essas dificuldades que, dessa forma mediatizadas, através de imagens e falas de personalidades, ganham um vulto ainda maior. A mídia também contribui para que seja construída uma desvinculação classista entre as pessoas. Essa desvinculação classista, isto é, que faz com que as pessoas não se sintam mais trabalhadoras e pertencentes a uma classe que vende seu trabalho, enfraquecendo sindicatos, perdendo força nas negociações, fazendo com que os direitos conquistados com muita luta, se tornem fragilizados, flexibilizados, líquidos (Bauman, 2001).

Problematização quanto ao tempo de formação, o modo como foram abordados alguns temas no manual e as possibilidades ou limitações que isso poderia trazer ao jovem

Será que o ensino bancário proposto pelo Projovem, apesar das melhores intenções dos professores, em um curso de curta duração (18 meses), para oferecer a formação correspondente aos 4 anos das séries finais, seria capaz de promover experimentação em novas formas de interação, apropriação de novos conhecimentos que sejam capazes de re-elaborarem suas próprias experiências e sua visão de mundo que se re-posicionem quanto à sua inserção social e profissional que ocorra inclusão social em seu sentido pleno? O tempo proporcionado ao jovem é suficiente para isso?

De acordo com Kuenzer (2006, p. 880),

já do ponto de vista da educação, estabelece-se um movimento contrario, dialeticamente integrado ao primeiro: por força de políticas publica professadas na direção da democratização, aumenta a inclusão em todos os pontos da cadeia, mas precarizam-se os processos educativos, que resultam em mera oportunidade de certificação, os quais não asseguram nem inclusão, nem permanência.

\section{Problemas em sala de aula}

O professor de qualificação profissional lia o manual em sala de aula e a professora de Ciências não sabia ou não lembrava o porquê de os elementos químicos estarem simbolizados na tabela periódica pelas letras ' $\mathrm{Pb}$ ', por exemplo, como é o caso do chumbo. Ela tinha curso superior em Zoologia e mestrado na mesma área.

Houve noites em que se iniciava as aulas com seis alunos e no final do período haviam apenas dois. A média de alunos em cada uma das quatro era de 10 alunos.

Problematização

Que tipo de seleção foi feita para esses casos específicos? Que tipo de formação receberam estes professores? Será que receberam?

Se o objetivo era incluir o maior numero possível de jovens, porque havia tão poucos alunos em sala de aula, enquanto que a sala da EJA estava repleta? 


\section{Atuação da professora de Ciências Humanas}

Nas aulas de Ciências Humanas, por exemplo, a professora se referia ao trabalhador assalariado como um consumidor, enaltecendo o sistema capitalista como aquele em que todos podem comprar com o seu salário o que desejar. Focaliza 0 interesse pelos celulares, há comentários da turma quanto à qualidade dos celulares, quais são os melhores. Também na página 28 do Guia de Estudo II, diz assim, considerando a evolução tecnológica do século 20 :

As inovações tecnológicas, a rigorosa divisão e especialização do trabalho favoreceram o aumento da produção e o acelerado crescimento industrial. Este processo de produção exigia, cada vez mais, novos consumidores para as mercadorias. Assim, nas modernas fábricas, o trabalhador assalariado tornou-se um consumidor de sua própria produção.

Entretanto, o que não foi esclarecido é que devido a isso o trabalhador é mais explorado, perdendo seu poder aquisitivo.

\section{Forma de avaliação: descrição e problematização}

O modo como foi instituída a avaliação, em que ao mesmo tempo em que menciona, nos termos da lei, que ocorre um acompanhamento durante todo o processo, contudo a mesma é invalidada, no sentido de haver uma vinculação ao Exame Nacional Externo com peso de $50 \%$ da avaliação total, desvinculando a avaliação externa do acompanhamento do aprendizado pelos professores, eximindo-os de sua responsabilidade, ou seja, o acompanhamento do aprendizado tem pouca ou mínima influência quanto ao Exame Nacional Externo, que é fornecido pela Universidade Federal do Paraná.

Por outro lado, o certificado é fornecido pela Secretaria Municipal de Educação de Canoas. Importante mencionar também o período de duração do programa, que não acompanha o ensino formal, sendo de 18 meses contínuos, isto é, sem período de férias. Sua data de início, em geral, é no final do ano letivo, em novembro.

O programa focaliza o desemprego como se fosse o problema principal, mas o que acontece na realidade é uma alfabetização funcional desde as séries iniciais, que dificilmente será resolvida em um curso de 18 meses, que se propõe, além da conclusão das séries finais do ensino fundamental, também a qualificação profissional inicial e ação comunitária nas suas atividades curriculares. O resultado disso é a inclusão excludente e subordinada dos jovens, num mercado de trabalho competitivo, incapaz de suportar sobrantes (Fonseca, 2007). Situação que não consegue fazer frente aos desafios encontrados no mundo do trabalho e nem com que se mantenham nele, muito menos na escola.

\section{Carga horária semanal}

Cada semana é organizada de modo a incluir, ao longo de todo o curso, 24 horas presenciais teórico-práticas, que podem estar assim distribuídas: elevação de escolaridade: 10 horas; qualificação profissional: 5 horas; ação comunitária: uma hora; informática: 2 horas; estudos/trabalhos interdisciplinares: 6 horas.

A cada semana há, também, oito horas de atividades não-presenciais, que são 
acompanhadas pelo professor-orientador, distribuídas pelos componentes curriculares, incluindo o Plano de Orientação Profissional - POP - e o Plano de Ação Comunitária PLA.

Aos professores orientadores cabe, de acordo com o programa, de acompanhar a evolução da turma. O que vi quanto ao acompanhamento foi uma das professoras colocando no quadro todas as atividades da semana e solicitando aos alunos que the dissessem como é que estão em relação às atividades. Não se caracterizaria essa atitude e a outra de aquiescência ao programa como uma educação bancária? Diz-nos Freire (1978, p. 4):

Metaforicamente, a educação bancária pode ser caracterizada como o procedimento metodológico de ensino que privilegia somente 0 ato de repetição e memorização do conteúdo ensinado. Assim, o professor, geralmente por meio de aulas expositivas, deposita na cabeça do aluno conceitos a serem cobrados, posteriormente, na prova, quando então, aquele obtém o "extrato" daquilo que foi depositado.

Há apenas uma cobrança no que se refere à execução de atividades, para que cumpram o programa. $\mathrm{O}$ aluno que não consegue acompanhar tem um dia por semana para tirar suas dúvidas, às sextas-feiras. Ao aluno não é dado muito espaço para pronunciar sua palavra e também é algo que, de antemão, apresentam alguma dificuldade, pelos traumas evidenciados, multirepetências, exclusão da escola.

Memórias dos alunos do Projovem: o primeiro abandonou os estudos na $8^{\text {a }}$ serie, o segundo na 6⿳⺈冂serie 
61

LEMBRO-ME VAGAMGNTE DA ÉPOEA EM COE FOI DLFAGGTRADO. COMECEI GN CASA, AOR VOLTA DOS Y ANOS

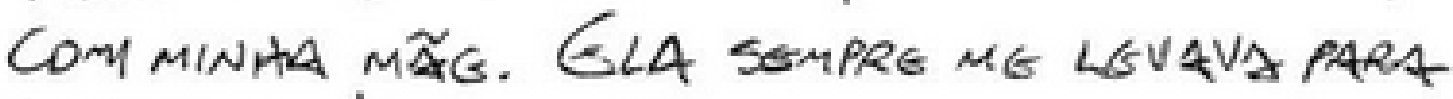
- QuARto NAO hora DG DORMir e MG CONTAVA HISTORINAHAS infantis, Das quats lembro mutio POUKO. LOGO GM SEGUIDA MG PASSAVA AS PRIMEIRAS LGTRAS DO ALIABGTO. COM UMA PACI ÉNCIA QNG Só MLÁE TGM. ATRAVǴS DISSO, TIVE MAIS Fa

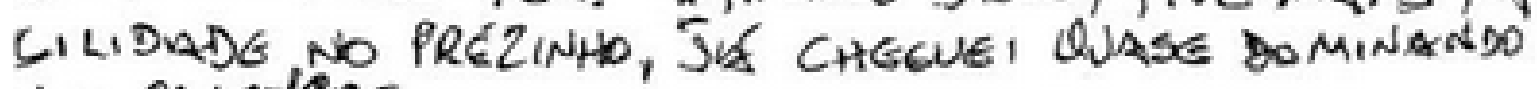
AS PALAVIRAS.

Na omtana série resolvi fazer a gaANDE BOBAGGM DE MINHA VITK: PARAR DE ESTUDAR PASA TRABALLHAR, ISTO 6 O due MG TRA2 AO PRO JONGM,

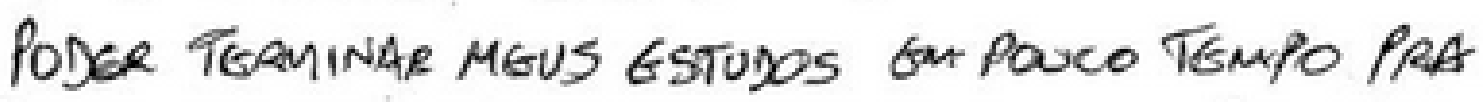

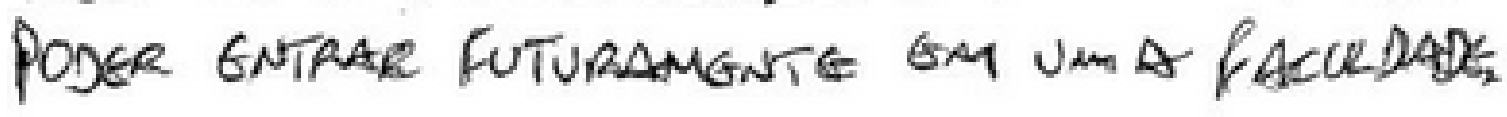

Regae: Rev. Gest. Aval. Educ.

Santa Maria

v. 3

ก. 5

Jan./jun. 2014

p. $51-63$ 


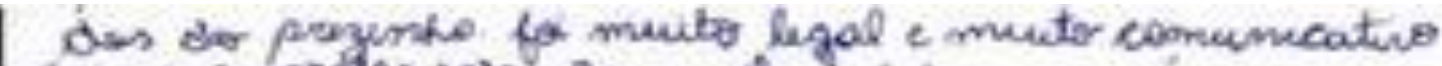

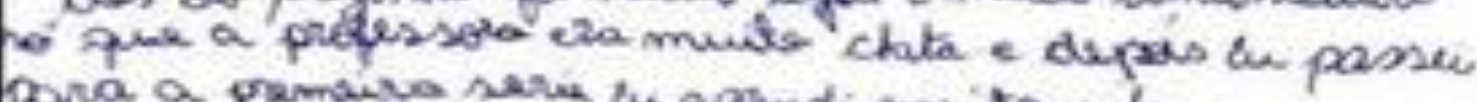

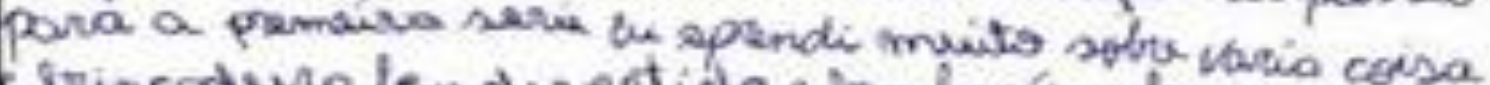

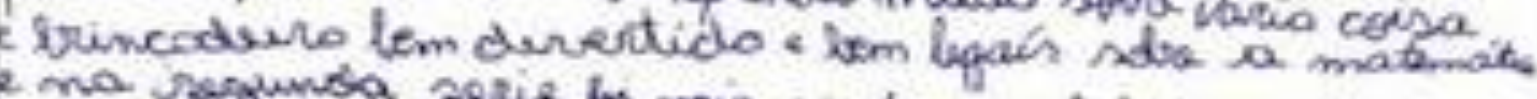
2 mo sergunca zerie for mois anda complicodo mais em

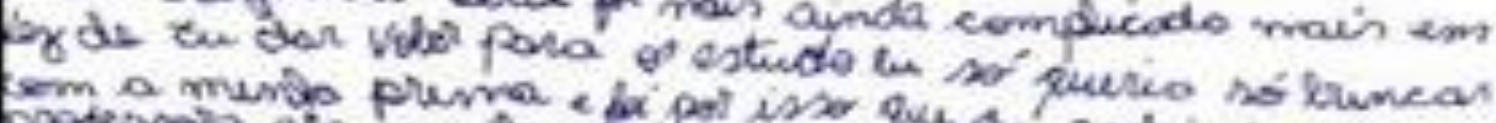

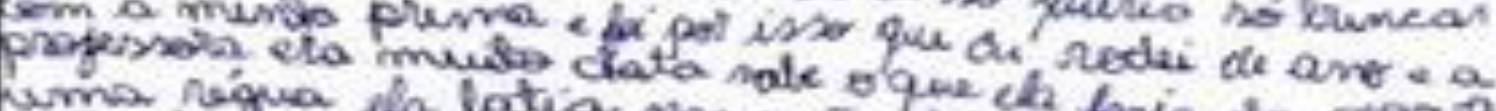

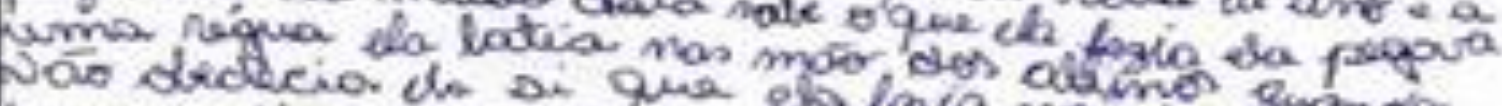

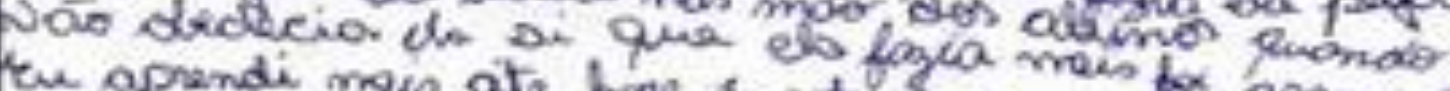

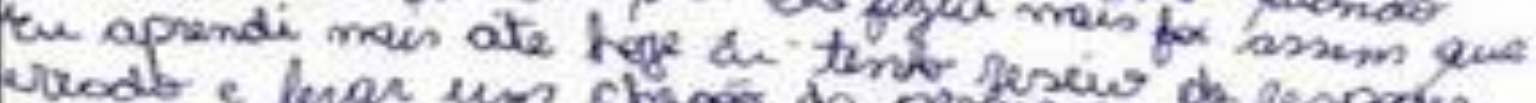

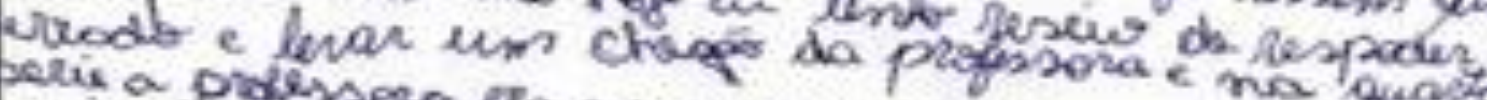

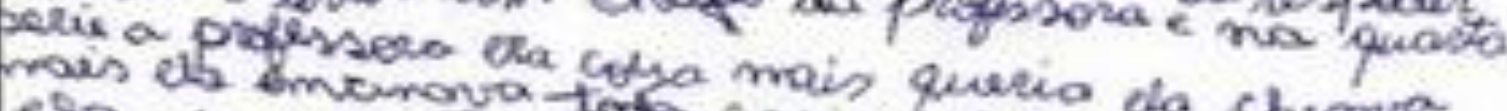

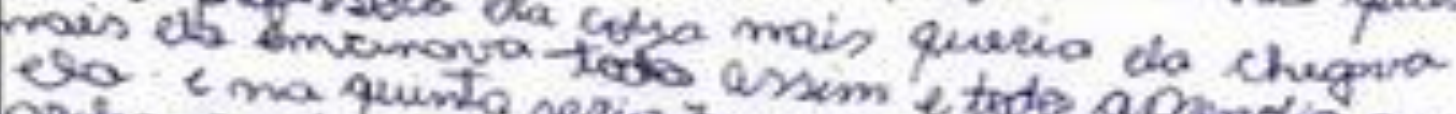

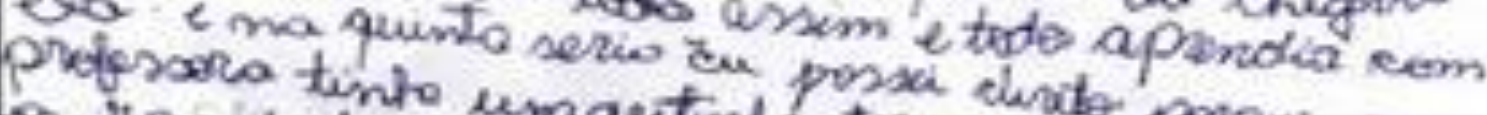

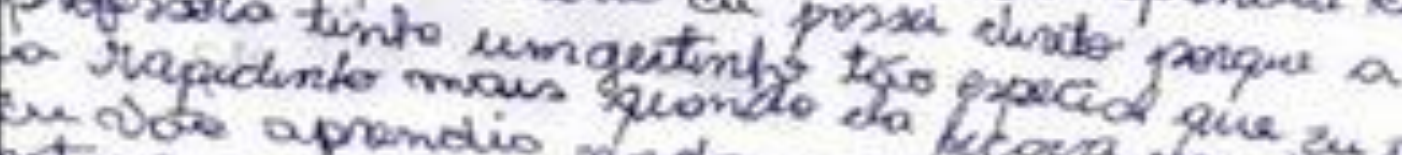

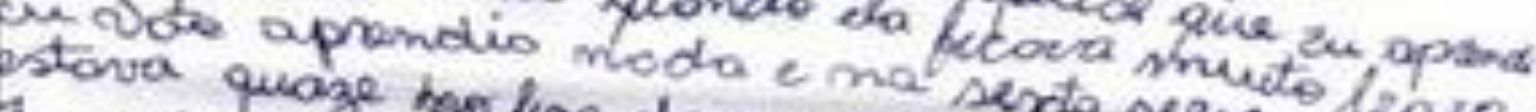

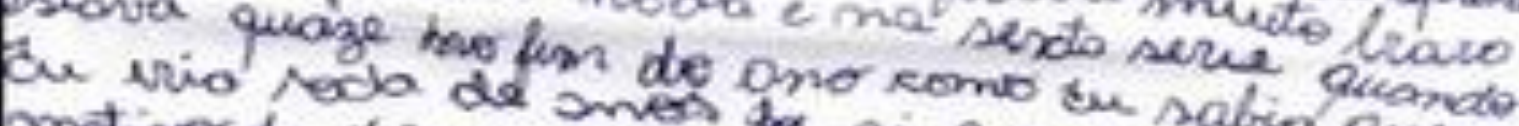

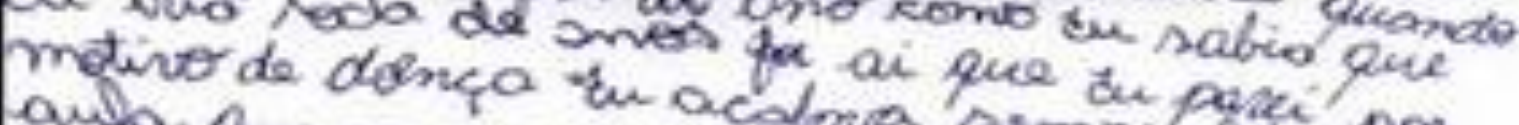

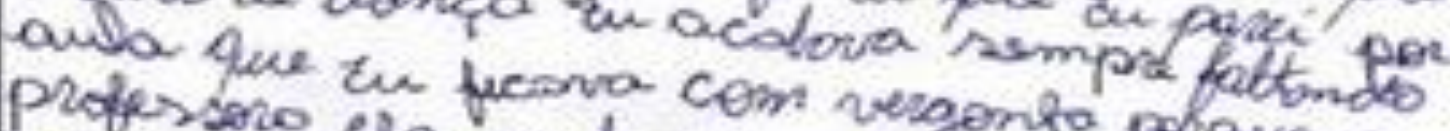

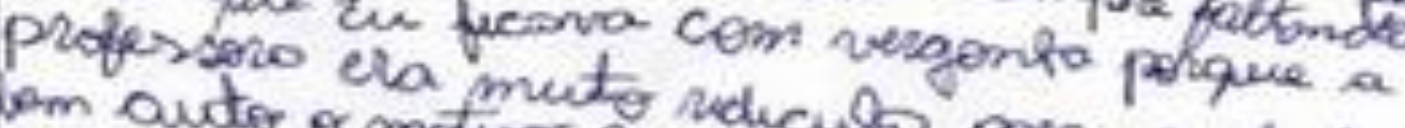

\section{Considerações finais}

Levando-se em consideração tudo o que contém este trabalho, podemos mencionar o Programa do Projovem como aquele que conduz ou direciona os jovens a um alfabetismo funcional, insuficiente para abarcar os objetivos de autonomia e cidadania ativa, participativa e consciente de seus direitos e deveres, capaz de transformar sua situação de exclusão como pretende o programa.

O modo como foi instituída a avaliação, que ao mesmo tempo em que menciona, nos termos da lei, que deve ocorrer um acompanhamento durante todo o processo, vincula-se a um Exame Nacional Externo com peso de $50 \%$ da avaliação total, desvincula a avaliação externa do acompanhamento do aprendizado pelos professores, eximindo-os de sua responsabilidade, ou seja, aqueles que acompanharam o aprendizado não têm nenhuma influência quanto ao Exame Nacional Externo. 
O Projovem anuncia mais uma farsa institucional, a de que por ele o aluno será reinserido no sistema formal de ensino, conseguindo dar continuidade aos estudos. Há muitas falhas no processo para que haja uma consecução dos objetivos embutidos nele e a maior falha é o próprio programa, instituído por medida provisória. Fere algumas leis da LDB no que se refere à formação requerida pelos professores, e também em relação aos conteúdos das séries finais do ensino básico.

Ao implantar um projeto que apresenta muito mais resultado na mídia do que de fato, poderá resultar em mais um programa de governo que se mostrou inadequado e insuficiente para os objetivos de inclusão escolar e no mundo do trabalho, ao contrário do que é propalado. O programa serve muito mais como uma justificativa para o governo, quanto ao gasto de verbas provenientes dos órgãos multilaterais.

\section{Referências}

BAUMAN, Zygmunt. Modernidade líquida. Rio de Janeiro: Jorge Zahar, 2001. FONSECA, Laura Souza. O trabalho mutilando o tempo infanto-juvenil. Mimeo., 2007 FREIRE, Paulo. Pedagogia da autonomia. Rio de Janeiro: Paz e Terra, 1996. FREIRE, Paulo. Pedagogia do oprimido. Rio de Janeiro: Paz e Terra, 1978.

KUENZER, Acácia Z. A educação profissional nos anos 2000: a dimensão subordinada das políticas de inclusão. Educação e Sociedade, Campinas, vol. 27, n. 96, 2006, p. 877910. Disponível em: http://www.cedes.unicamp.br> Acesso em: 13 mar., 2007.

Programa Nacional de Inclusão de Jovens - Projovem. Documentos. Disponível em: http://www.Projovem.gov.br Acesso em: 15 abr.2007.

RIBEIRO, Vera M. M. Alfabetismo funcional: referências conceituais e metodológicas para a pesquisa. Educação \& Sociedade, ano XVIII, n. 60, 1997, p. 154-158.

SALGADO, Maria Umbelina C. Projovem - Unidade Formativa I, Guia de Estudo. Brasília: Presidência da República, Secretaria Geral, 2005.

SALGADO, Maria Umbelina C. Projovem - Unidade Formativa II, Guia de Estudo. Brasília: Presidência da República, Secretaria Geral, 2005.

Maria da Luz Cavasotto Botao é professora da educação infantil. Endereço: Avenida Guido Mondin, 396 - 90230-260 - Porto Alegre - RS - Brasil. E-mail: marialuzcb@ig.com.br.

Recebido em 20 de junho de 2013.

Aceito em 27 de março de 2014. 